\title{
PÍLDORAS PARA SALVAR LA CONSTITUCIÓN DE 1991 (I PARTE). EXCESOS DE LA DEMOCRACIA PROCEDIMENTAL Y ESCASEZ EN LA REPRESENTACIÓN ARGUMENTATIVA
}

\section{Fernando Aurelio Guerrero Cárdenas}

Abogado, Mag. en Litigio Internacional en Derechos Humanos y Derecho Internacional Humanitarios Universidad Santo Tomás-Bogotá (Colombia); Esp. Derecho Administrativo, Universidad Santo TomásBucaramanga (Colombia). Esp. Derecho Constitucional en curso, Universidad Santo Tomás-Bucaramanga (Colombia); Asesor Jurídico en Derecho Constitucional de la Segunda Vicepresidencia del Senado de la República de Colombia.

E-mail:fernandoguerreroc@hotmail.com

\section{Resumen}

En este escrito se intenta proporcionar un punto de partida para una descripción adecuada del diagnóstico sobre los riesgos que presenta la flexibilidad en el ingreso de nuevas disposiciones a la Constitución Nacional colombiana, al reflexionar desde el caso de la "reforma a la justicia" que muestra la iniciación del ejecutivo como guardián material de las reformas y la reciente Sentencia de control constitucional a un Acto Legislativo que resalta los elementos introducidos al derecho fundamental de la acción de inconstitucionalidad contra enmiendas por vicios de competencia parlamentaria. Finalmente, se describe el rastreo de una doctrina preliminar que asume la problemática de las tensiones entre el principio democrático y la supremacía de la Constitución.

Palabras Clave: Sustitución de la Constitución, democracia constitucional, dogmática jurídica, derechos fundamentales.

\begin{abstract}
In this paper, we attempt to provide a starting point for an adequate description of the diagnosis on the risks presented by the flexibility in the entry of new provisions to the Colombian Constitution, reflecting for the case of "justice reform" showing guardian executive income as material and the recent reforms Judgment control a legislative constitutional highlighting the elements introduced to the fundamental right of unconstitutionality against amendments by parliamentary competition vices. Finally we describe the preliminary screening of a doctrine that takes the issue of tensions between the principle of democracy and the supremacy of the Constitution.
\end{abstract}

Keywords: Replacing the Constitution, constitutional democracy, legal doctrine, fundamental rights

\section{Riassunto}

In questo lavoro, cerchiamo di fornire un punto di partenza per una descrizione adeguata della diagnosi sui rischi presentati dalla flessibilità in ingresso di nuove disposizioni della Costituzione colombiana, che riflette per il caso di "riforma della giustizia" che mostra Guardiano reddito esecutivo come materiale e la recente sentenza riforme controllo di mettere in evidenza gli elementi legislativi costituzionali introdotte per il diritto fondamentale di incostituzionalità contro gli emendamenti di vizi concorrenza parlamentari. Infine si descrive lo screening preliminare di una dottrina che prende la questione delle tensioni tra il principio della democrazia e della supremazia della Costituzione.

Parole Chiave: Sostituzione della Costituzione, la democrazia costituzionale, la dottrina giuridica, i diritti fondamentali. 

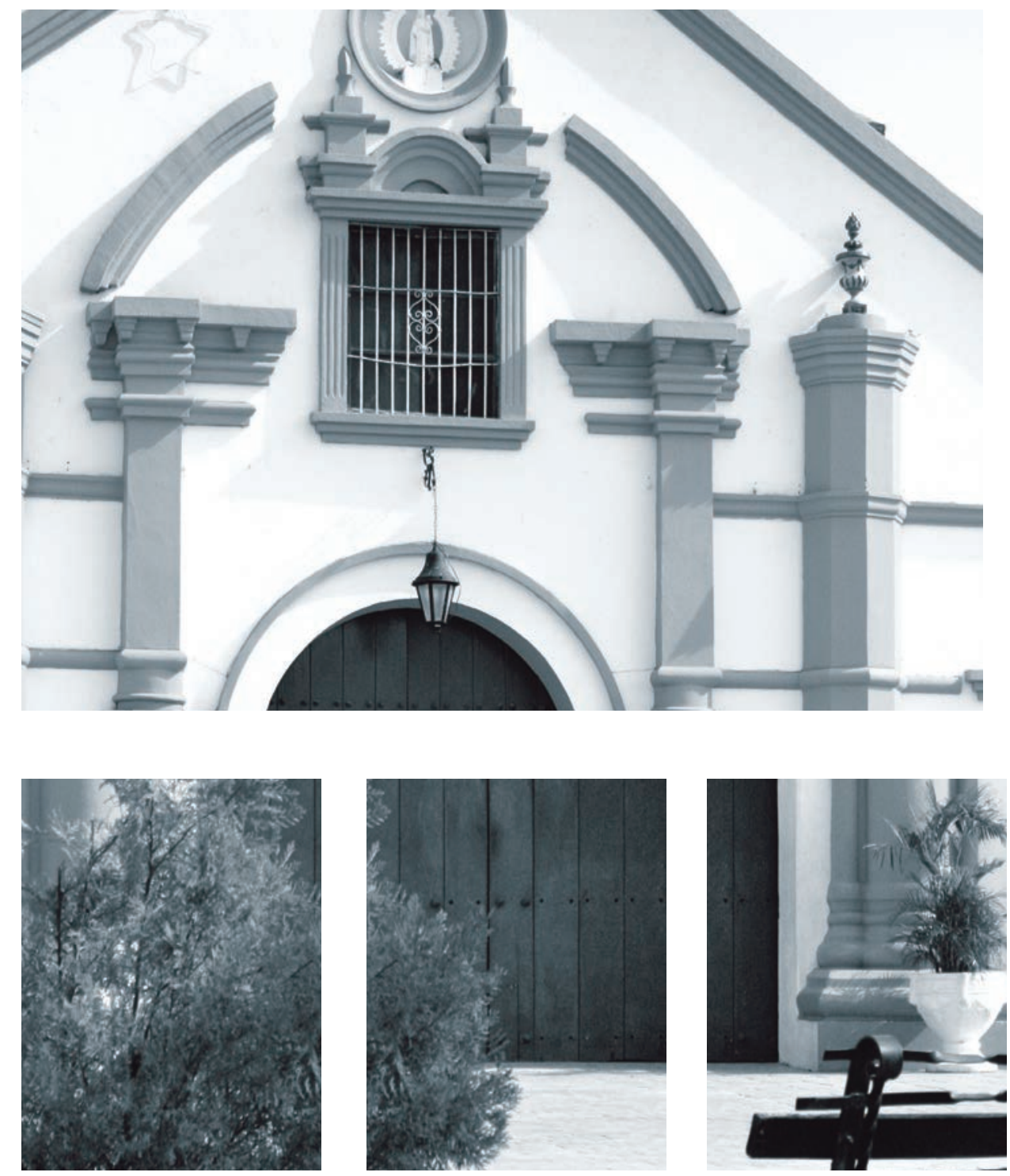

Iglesia de Santa Bárbara - Mompóx - Colombia

Martín Emilio Hernández Manrique 


\section{PÍLDORAS PARA SALVAR LA CONSTITUCIÓN DE 1991 (I PARTE). EXCESOS DE LA DEMOCRACIA PROCEDIMENTAL Y ESCASEZ EN LA REPRESENTACIÓN ARGUMENTATIVA*}

Fernando Aurelio Guerrero Cárdenas

\section{Consideración previa}

"La Constitución de 1991, pone a la contemporaneidad en el mismo pupitre, a funcionarios y a ciudadanos, a alumnos y profesores" JUAN CARLOS HENAO

Del seguimiento al oficio legislativo colombiano de la última década en

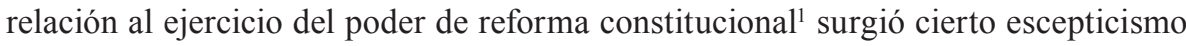
principalmente por el reciente ejercicio de control constitucional del ejecutivo al polémico proceso de reforma constitucional conocido en mass media como "reforma

* El presente escrito se encuentra dentro del contexto de las investigaciones desarrolladas para la Segunda Vicepresidencia del Senado de la República de Colombia del 2011-2012 en relación a la necesidad de estudiar el fenómeno de la Doctrina de la Sustitución de la Constitución proporcionada por la Corte Constitucional y el seguimiento en ese sentido al VII Encuentro de la Corte Constitucional del 2011.

1. Una reconstrucción sobre la línea jurisprudencial del control a las reformas constitucionales en CAJAS, Mario, El control judicial a la reforma constitucional. Colombia, 1910-2007, edición de la Universidad ICESI de Calí, 2008, que incluye la época de la Guerra de los Mil Días, con paso a las distintas reformas a la Constitución de 1886, hasta la polémica introducción de la relección presidencial en la Constitución de 1991. 


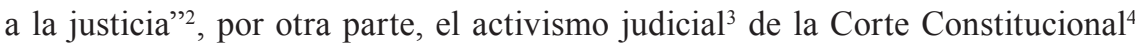
al controlar los excesos del legislativo han producido cierta desconfianza ya que no han logrado definir la doctrina de justiciabilidad de las reformas. Los límites ${ }^{5}$ a la democracia procedimental no son claros especialmente cuando se evidencia en sus actores cierto caudillismo, y respecto a los márgenes de discrecionalidad para la interpretación de la norma primaria ${ }^{6}$ por parte del máximo Tribunal Constitucional, comportan posturas contradictorias y opuestas, incluso entre los mismos magistrados que componen la Corte Constitucional.

El tema es ausente de claridad axiológica, dogmática, e incluso teórica, e incluye diferentes posturas, situándose los más progresistas dentro del contexto del actual cambio de paradigma que incorpora un nuevo concepto de Constitución y un asentamiento del Estado Constitucional, y los más escépticos dentro del criticismo al proceso de racionalización que no da respuesta integral y eficaz a las demandas generalizadas de una especie de violencia estructural ${ }^{7}$.

2 Proyecto de Reforma Constitucional Acto Legislativo No. 07 de 2011 de Senado, 143 de 2011 de Cámara, acumulado con los proyectos de Acto Legislativo No. 09 de 2011 Senado, Acto Legislativo No. 11 de 2011, Acto Legislativo No. 12 de 2011 de Senado y Acto Legislativo No. 13 de 2011 Senado.

3 El italiano y juez Gustavo Zagrebelsky en su texto Principios y votos. El tribunal Constitucional y la Política, explica este fenómeno cuando confiesa que la función judicial es altamente política sin pertenecer a la política, que penetra la esencia de la democracia sin ser una función derivada de la democracia directa, pero afirma que frente a un vacío relacionado con la extralimitación del ejercicio del poder y las degeneraciones de la democracia, un Tribunal Constitucional está llamado a ser el defensor de los principios fundamentales.

4 La reforma constitucional ha tenido históricamente épocas emblemáticas de control, dentro de la vigencia de la Constitución de 1886. A partir de 1910 la Corte Suprema de Justicia como ente de control constitucional enfrentó un período particular de trámites de enmiendas constitucionales entre los años 1955 y 1990, debió dirimir estos temas bajo la rigidez funcional estipulada en la Constitución de 1886, evidenció en algunas Sentencias cierto activismo, y dejó rastros de preferencia de la deliberación del fondo de una reforma por el parlamento.

5 En ese escrito se tendrán como límites los de tipo axiológico y lógico, sin desconocer que existen otros. Sobre ellos ver al profesor RAMÍREZ, Gonzalo en La reforma constitucional y las garantías del poder constituyente: los derechos fundamentales como paradigma de la Revista Temas de Derecho Público No. 69, Universidad Externado de Colombia, Bogotá, 2003; Ver también la clasificación de Pedro de la Vega expuesta por CARBONELL, Miguel, en Reforma Constitucional. Límites y Controles, UNAM No. 12011.

6 Según el jurista Mexicano HERNÁNDEZ, Juan Albelardo, en su texto Argumentación Jurídica publicado por Oxford University Press, una norma constitucional que presente una opción como absolutamente necesaria para que se cumpla una segunda, aplica como operador lógico bicondicional (incluido por Ludwig Wittgenstein en las Tablas de Verdad) y no aborda las debarim o enunciados orientados a acciones. Este es el caso del artículo 241 de la Carta Constitucional Colombiana referente a la competencia de la Corte frente al control de las reformas constitucionales, ejemplo de cláusula bicondicional.

7 FAMER, Paul, Patologías del Poder. Salud, Derechos Humanos, y la nueva guerra contra los pobres. Ver también, SEN Amartya Kumar, Desarrollo y Libertad, Editorial Planeta, 2000. 
Para no exceder los propósitos de este trabajo sólo se intentará introducirse a este debate $^{8}$, para realizar un diagnóstico de la enfermedad para futuros remedios, hacer un inventario de los síntomas desde unos casos concretos, que den base, armazón y material para la reflexión y futura descripción del problema, para lo cual, en primer lugar, se aborda un acercamiento estructural y jurídico al emblemático caso de la "reforma a la justica", se realiza una reconstrucción de la Sentencia más reciente de la Corte sobre la doctrina constitucional de la sustitución y se finaliza con una proyección preliminar sobre el rastreo de la doctrina que ha asumido la paradoja.

\title{
2. Reforma a la justicia: el mito de la constitución rígida y el activismo metaconstitucional del ejecutivo
}

\author{
"La falla más grande de la \\ Constitución colombiana, es la facilidad extrema con la que \\ se puede tramitar una modificación constitucional"
}

JON ELSTER

Hay una mirada escéptica hacia el Congreso y la Corte Constitucional, ya que se desconfía de la capacidad del legislativo de respetar los límites constitucionales al poder derivado de reforma, y de la eficacia funcional de la Corte para ejercer control constitucional a los excesos del legislativo. Frente a estas deficiencias y el ritmo acelerado de reformas, ingresa el ejecutivo como guardián de la Constitución, al denunciar recientemente por inconveniente e inconstitucional el proceso deliberativo reciente, que intentó reformar pluralidad de artículos de la Constitución relacionados directa e indirectamente con la Administración de Justicia.

Sin entrar a cuestionar o no la función de control constitucional del ejecutivo, la denuncia al Proyecto de Acto Legislativo No. 7 de 2011, reveló la ausencia de límites 9 claros al poder derivado de reforma constitucional, ahora más amplia con la introducción del Acto Legislativo 01 de 2011 a la Constitución, al abolir el régimen de impedimentos y conflictos de interés cuando los congresistas votan reformas constitucionales. Puede decirse que los cuestionamientos a la "reforma a la justicia" que generan la desconfianza provienen de tres bloques temáticos.

8 Debate en el que todos tienen derecho a participar según PRIETO, Luis, en Notas sobre la Interpretación Constitucional, Revista del Centro de Estudios Constitucionales, mayo-agosto 1991, Universidad de Castilla-La Mancha.

9 Estos tipos de límites se adecuan hacia los llamados límites circunstanciales distintos a los límites meramente formales, los cuales surgen del cuestionamiento de las discusiones democráticas. CAJAS, Mario, en La Reforma Constitucional: Límites de La Corte al Congreso explica este tipo de límites y expone que pueden ser derivados de prescripciones explícitas de las Cartas Políticas o de aspectos axiológicos de la misma. 
En primer lugar el proceso de reforma constituciona $1^{10}$ no se estructuró con fiel seguimiento al principio de unidad de materia que exige el art. 158 de la Constitución Nacional, además el proceso de gestación de la enmienda abstrae e incluye artículos sin la guía del principio de consecutividad y los propósitos del artículo 176 del Reglamento del Congreso que adiciona incluso en la etapa final del proceso contenidos en beneficio de los altos magistrados de la Rama Judicial e involucra a los magistrados de la Corte Constitucional, y en consecuencia impidiéndoles pronunciarse posteriormente sobre el estudio del test de Sustitución al Acto Legislativo, y derivando dicho estudio en jueces ad-hoc.

Como segundo punto se tiene que la actuación de la Presidencia de la República como evidente cuestionamiento al poder derivado de reforma constitucional, que a pesar de deliberar en ocho (8) debates el Acto Legislativo, las razones de inconveniencia e inconstitucionalidad descritas bajo la figura de objeciones presidenciales $^{11}$ (que requirió solicitud y autorización para la celebración de Sesión Extraordinaria ${ }^{12}$ ), sentó precedente frente a reformas constitucionales, sin requerir estudios de test de sustitución en sentido estricto. Esto dio un giro a la hermenéutica constitucional, que incluye el control político como control constitucional válido, pues surge un nuevo intérprete válido y legitimado, que da paso a la construcción de la hermenéutica constitucional que justifica la interpretación y ponderación de principios constitucionales ${ }^{13}$ por parte del ejercicio del poder ejecutivo.

Un tercer grupo de cuestionamientos tiene que ver especialmente con los despropósitos de la reforma. Los excesos se evidencian por intentar introducir en la Constitución la autorización para regular a través de una Ley la facultad particular de administrar justicia, que los presidentes de las Cortes fueran los administradores de los dos (2) billones de pesos anuales durante seis (6) años, con riesgo de quebrar el

10 SCHIMITT, Carl, en Teoría de la Constitución, señala que la dificultad de una reforma constitucional es una característica formal de la Ley Constitucional, donde los cambios constitucionales están sometidos a un procedimiento especial con condiciones más difíciles, para proteger la duración y estabilidad de las leyes constitucionales y aumentar su fuerza legal.

11 La Federación Nacional de Comerciantes, FENALCO en su Página virtual, tiene un link donde se puede descargar el texto de las Objeciones Presidenciales elevadas al proyecto de Acto Legislativo No. 143 de 2011 Cámara, 07 de 2011 Senado -acumulado con los proyectos de acto legislativo No. 9 de 2011 Senado, 11 de 2011 Senado, 12 de 2011 Senado y 13 de 2011 Senado- "por medio del cual se reforman artículos de la constitución política con relación a la administración de justicia y se dictan otras disposiciones.

12 Decreto 1351 de 2012, por medio del cual se convoca a sesiones extraordinarias al Congreso, el cual fue demandado ante la Corte Constitucional y junto con el texto conciliado y después aprobado por las plenarias de Cámara y Senado y listo para su publicación, admitiéndose su estudio sin admitir que el proyecto de acto legislativo impugnado esté en vigencia o produzca efectos jurídicos.

13 Sobre el origen de la ponderación de principios ver ALEXY, Robert, Derechos fundamentales, ponderación y racionalidad, en Revista Iberoamericana de Derecho Procesal Constitucional No. 11 enero junio 2009, p. 3-14, o en Canon Neoconstitucional, editado por CARBONELL, Miguel y GARCÍA, Leonardo, Universidad Externado, 2010, pp. 97-109 
principio de separación de poderes y las funciones judiciales del Estado al obligarla a presentar un proyecto para lograr la adjudicación de los recursos anualmente. Estos cuestionamientos como son el quebrantamiento de los principios de unidad de materia, de consecutividad y de autonomía de la justicia, entre otros, pueden ser vistos con mayor claridad si se estudia la estructura del Acto Legislativo.

La estructura de la "reforma a la justicia" puede estudiarse a su vez desde dos categorías una, respecto a la naturaleza de sus artículos y otra, respecto a su contenido. La primera categorización distingue cuatro tipos de artículos, los que crearían disposiciones constitucionales nuevas, los artículos que incluirían disposiciones constitucionales transitoriamente, los artículos que crean y modifican la nominación de los títulos de la Constitución y los artículos que desconstitucionalizarían funciones y crean órganos nuevos.

Una segunda categorización puede distinguir cinco bloques normativos. Un primer bloque de artículos relacionados con la desconstitucionalización y desmonte del Consejo Superior de la Judicatura (Enmienda a los Arts. 116, 156, 197, 231, 235, 254, 255, 256, 256a nuevo, 257, 257a nuevo); un segundo conjunto de artículos relacionados con las herramientas para posibilitar la descongestión judicial (Adición a los Arts. 116 sobre facultades legales para atribuir función judicial, 228 sobre presupuesto); un tercer grupo de artículos relacionados con la administración de justicia en sede legislativa (adición en los Arts. 174, 175, 178, 235); el cuarto bloque respecto a los artículos relacionados con la justiciabilidad de los Congresistas (Arts. 183, 184, 186, 235, 277; un quinto bloque de artículos sin línea temática común en el Acto Legislativo (Arts. 28 sobre detención preventiva para inimputables, 201 sobre política criminal, 228 sobre el derecho al acceso a la justicia y la autonomía de la rama, 229 sobre el arancel judicial, 232 sobre los requisitos para ser magistrado, 233 sobre el periodo de los magistrados e inhabilidad, 235 sobre nuevos aforados de juzgamiento y facultades legislativas de la CSJ, 250 sobre ampliación del tiempo del habeas, $257 \mathrm{~b}$ nuevo en relación con la creación del consejo de política criminal, 64 transitorio sobre salarios judiciales, $284 \mathrm{~b}$ nuevo sobre inhabilidades).

Estas categorizaciones sirven para realizar un juicio más claro al Acto Legislativo, lo cual no es la ambición en este escrito, aquí se toman junto con los cuestionamientos para intensificar ${ }^{14}$, la necesidad de una mayor atención a cómo el Congreso aborda las cuestiones constitucionales, a su papel en la interpretación constitucional, a los criterios mínimos para su integración en relación con la comprensión de la práctica constitucional, a cuales podrían ser las estrategias para una amplia rendición de cuentas al funcionamiento de reformas del Congreso, al papel de las oficinas de los legisladores para ayudar a aprender sobre cuestiones constitucionales, a la voluntad del Congreso frente a la influencia en decisiones constitucionales del poder

14 WHITtingtON, Keith, en Princeton University, concurrentemente trabaja los temas complejos derivados de la interpretación constitucional, incorporando el grado en que los tribunales podrían participar en lo que denomina en El Congreso y la Constitución, la construcción constitucional. 
ejecutivo, e incluso a las estadísticas sobre la frecuencia con la que toman en cuenta las cuestiones constitucionales.

Este diagnóstico preliminar se trata si se quiere una denuncia de caso que identifica la especial gravedad del tema y justifica los síntomas de desconfianza y escepticismo en quienes se confía el poder derivado de reforma.

\section{Racionalidad del derecho fundamental de la acción de inconstitucionalidad} “(la) función creadora del juez (...) se realiza mediante la construcción y ponderación de principios de
derecho (...) la labor del juez no pueda reducirse a una simple atribución mecánica de los postulados generales, impersonales y abstractos consagrados en la ley a casos concretos..."

S C-836 de 2001 /MP: RODRIGO ESCOBAR GIL

La Corte Constitucional en la última década ha enfrentado un considerable número de reformas constitucionales que generan múltiples estudios de control constitucional con diferentes resuelves en sus Sentencias. Una reconstrucción de la línea jurisprudencial que dibuje la doctrina constitucional relacionada con los límites del poder de enmienda no es la intención de este trabajo ya elaborado por otros, limitaré el estudio detallado de la más reciente Sentencia de control constitucional en un intento de recoger algunos elementos para el análisis y un posterior trabajo.

Recientemente el Magistrado Ponente Jorge Iván Palacio Palacio estudió el caso de la conocida "desconstitucionalización de la comisión nacional de televisión", producto del Acto Legislativo No. 2 de 2011 que derogó el artículo 76 y modificó el artículo 77 de la Constitución Política de Colombia y concretó en la Sentencia C-170 de $2012^{15}$ varios criterios para un estudio de control constitucional y reconstruye el

15 Esta es la primera de las múltiples sentencias que se esperan como control constitucional a las reformas realizadas en el último año, como la del conocido como "marco constitucional para la paz", la descentralización de las regalías, el principio de sostenibilidad fiscal y reforma del fuero militar, entre otras. Anteriores a este fallo también se tienen entre otras la Sentencia C-1200 de 2003 sobre las facultades extraordinarias al Presidente de la República para modificar la Ley Estatutaria de Administración de Justicia, La Ley Estatutaria de Habeas Corpus, el Estatuto Orgánico de la Fiscalía y varios códigos, con el fin de adecuarlos al sistema penal acusatorio; la Sentencia C-816 de 2004 sobre el Acto Legislativo 2 de 2003; la Sentencia C-970 de 2004 la Corte analizó el Art. $4^{\circ}$ transitorio del Acto Legislativo 3 de 2002, que facultó al Presidente de la República para expedir normas con fuerza de ley encaminadas a la implementación del sistema penal acusatorio, declarando su exequibilidad, resaltándose en su razonamiento que "Una cosa es alterar un principio fundamental y otra distinta sustituir un elemento definitorio de la identidad de la Constitución"; la Sentencia C-971 de 2004 sobre el Acto Legislativo 1 de 2003; la Sentencia C-1040 de 2005 donde entre otras cosa reconoció que "el proceso de elaboración doctrinaria sobre la materia se encuentra en curso" y declaró inexequible la habilitación al Consejo de Estado para que de manera supletoria expidiera normas con fuerza de Ley Estatutaria, por ser un elemento integralmente diferente a los que definen la identidad de la Carta, y supone una sustitución parcial y 
método del juicio de sustitución.

Es de resaltar en primer lugar de esta Sentencia que con el sólo hecho de haberse admitido la demanda, se aceptó la existencia de una necesidad de estudiar la constitucionalidad de la reforma por vicios formales de incompetencia del legislativo, ya que los cargos en la demanda reseñaban exclusivamente dichos argumentos. Se señaló que la presentación de un vicio de competencia por exceso en el poder de reforma constitucional es conforme a la Sentencia C-1200 de 2003 siempre y cuando se presenten elementos que justifiquen un estudio sobre la magnitud y trascendencia de dicha reforma que conducen a que la Constitución haya sido sustituida por otra, así también lo estipula y lo amplia la Sentencia C-599 de 2010.

Este primer punto lo identifica el Magistrado Humberto Sierra Porto al salvar su voto y apartarse del razonamiento de la Corte en general, ya que según él da paso a la consolidación de premisas para examinar vicios de competencia de los actos reformatorios de la Constitución, avanza sobre un concepto de Constitución material y una interpretación que desvalora el contenido textual o literal de diversos preceptos constitucionales. Esta crítica a pesar de ser fecunda sobre todo respecto a la posible labor desbordada del intérprete y los límites constitucionales que evitan excesos y desbordes hermenéuticos, sirve igual para defender y avanzar en fundamentar el decisionismo judicial cuando busca salvaguardar la Constitución misma. Sin esos excesos judiciales algunos excesos legislativos no tendrían reparos para su introducción en la Constitución.

Un segundo punto para resaltar es que se sienta la tesis del ejercicio soberano de las personas del derecho fundamental a la acción de inconstitucionalidad por el contenido de una reforma, explicándosele que deberá introducir algunos elementos adicionales a una demanda de inconstitucionalidad a una Ley en particular, ya que se enfrenta un juicio contra un texto que ya hace parte de la Constitución Política, es decir, que ya está materialmente incorporado a ella. Así la Corte explica que este tipo de acción debe tener una mayor carga argumentativa que la que tiene la acción por inconstitucionalidad de una Ley infraconstitucional, y que se debe demostrar la sustitución o derogación de la Norma Superior justificando plenamente y de manera suficiente con argumentos claros, ciertos, específicos y pertinentes, que el cambio introducido por el Congreso de la República (órgano constituido), implica la

temporal de la Constitución; la Sentencia C-153 de 2007 sobre el Acto Legislativo 1 de 2005 donde aclaró que toda reforma supone un cambio que puede ser sustancial o radical; la Sentencia C-757 de 2008 estudió el Acto Legislativo 1 de 2007; la Sentencia C-588 de 2009 que declaró inexequible por vicio de sustitución el Acto Legislativo 1 de 2008, donde introdujo los conceptos de destrucción, supresión, quebrantamiento y suspensión de la Constitución, como vías a través de los cuales puede configurarse una sustitución de la Carta Política; la Sentencia C-141 de 2010 la Corte que declaró inexequible la Ley 1354 de 2010 mediante la cual se convocaba a un referendo para permitir una segunda relección del Presidente de la República; y la Sentencia C-303 de 2010 respecto al Acto Legislativo $1^{\circ}$ de 2009. 
abrogación de la Constitución Política vigente ${ }^{16}$. Recientemente en la Sentencia C-317 de 2012 la Magistrada Ponente la Dra. María Victoria Calle Correa sobre el control constitucional al Acto Legislativo 05 de 2011 por el cual se constituye el Sistema General de Regalías, también resaltó la exigencia de la especial carga argumentativa calificada para imputar un cargo de sustitución parcial de la Constitución Política.

Así las cosas, una demanda de inconstitucionalidad por el contenido, debe demostrar con suficiente solvencia cuál es el pilar o pilares esenciales de la Carta que se consideran sustituidos, por qué estos son definitorios de la identidad de la Constitución, cuál es el nuevo elemento introducido en la reforma, y por qué dicho elemento remplaza o sustituye el anterior de manera tal que lo hace definitivamente incompatible, a tal punto que desnaturaliza la estructura básica del ordenamiento supremo ${ }^{17}$. En síntesis, su objetivo es demostrar que el Congreso de la República al aprobar un Acto Legislativo excedió sus límites de reforma constitucional ${ }^{18}$ y configuró el presupuesto formal de vicio de competencia por sustitución de un pilar básico de la Constitución.

Una reconstrucción de las premisas de la Sentencia C-574 de 2011 concreta lo que tiene que tenerse en cuenta si se pretende motivar un estudio de control constitucional al legislativo por la producción de un Acto Legislativo:

a. Una demanda de inconstitucionalidad es por esencia una demanda por un vicio formal que puede estar relacionada con la competencia si lo que se quiere es proponer un juicio de sustitución.

b. Una demanda de este tipo no puede sobrepasar el término de caducidad de un año establecido en los artículos 242.3 e inciso final del artículo 379 de la C.P.

c. La competencia de la Corte sobre el análisis de la demanda estará únicamente determinada por los cargos establecidos en ella.

d. El juicio de sustitución no es un juicio de intangibilidad ni tampoco un juicio de un contenido material de la Constitución, no constata una contradicción entre normas, ni verifica si se presenta la violación de un principio o regla intocable.

e. El objetivo de la Corte es comprobar que el elemento esencial revelado es un límite material intocable por el poder de reforma.

f. El concepto de sustitución no es un concepto completo, acabado o

16 Según la Corte el incremento de la carga argumentativa se justifica por cuanto "se trata de la impugnación contra una reforma constitucional elaborada por un órgano que representa al pueblo (C. Po. Arts. $3^{\circ}$ y 133), conforma una de las tres ramas del poder público (C. Po. Art. 113), ejerce función constituyente (C. Po. Art. 114) y, en general, está habilitado para introducir reformas a la Carta Política, dentro de los límites establecidos por el propio constituyente".

17 La Corte, sin embargo, no desconoce que el principio pro actione es omnipresente en los procesos de naturaleza pública y en particular en el ejercicio de la acción de inconstitucionalidad y que el "examen de los requisitos adjetivos de la demanda no debe ser sometido a un riguroso escrutinio y se debe preferir una decisión de fondo antes que una inhibitoria, de manera que se privilegie la efectividad de los derechos de participación ciudadana y de acceso al recurso judicial efectivo ante esta Corte".

18 La Corte acoge la tesis de los límites competenciales al poder de reforma desde la Sentencia C-551 de 2003 
definitivamente agotado, no existe un conjunto total de hipótesis que lo caractericen.

g. El control de constitucionalidad de sustitución es un control de tipo inductivo y no deductivo.

La acción diría el profesor Joel Colón Ríos ${ }^{19}$ busca la declaración de inconstitucionalidad de una enmienda constitucional por parte de un Tribunal Constitucional, tesis novedosa en el ámbito internacional, que implica aceptar la revisión del trabajo de reforma de las mayorías parlamentarias, enfrenta un grado y un nivel de complejidad superior a un simple juicio de Control del procedimiento formal, poniéndose el acento en la argumentación y la interpretación, de esta se deriva el poder desvirtuar que se está en presencia de una reforma y que por lo contrario se está frente a una sustitución, para lo cual cabe preguntarse qué es una reforma constitucional y cuál es su diferencia con otros fenómenos, entre ellos la sustitución de la Constitución o la destrucción de su estructura básica, o la subversión de su integridad, que tendría un efecto creativo de una Constitución nueva, facultad o soberanía ineludible sólo al poder originario ${ }^{20}$.

Del mismo modo la acción requiere fundamentar la competencia para ejercer un Control Constitucional, siguiendo la interpretación lógica y axiológica de la norma constitucional que le ordena ejercer sólo control formal en sentido estricto ${ }^{21}$,

19 Actualmente el profesor puerto riqueño Joel Colón Ríos, por su tesis doctoral en derecho The Legitimacy of the Juridical: Weak Constitutionalism, Democracy, and Constituent Power, es considerado una autoridad sobre los estudios de la relación entre democracia, poder constituyente y cortes constitucionales en los procesos de reforma constitucional y elaboración de nuevas constituciones. Sobre este tema ha publicado recientemente los papers "Democracy and Constitutional Change" y "The Legitimacy of the Juridical: Constituent Power, Democracy, and the Limits of Constitutional Reform".

20 'La Corte Constitucional se adhiere a la tesis planteada por Carl Schmitt en su texto Teoría de la Constitución que afirma que el otorgar al poder de reforma la facultad de modificar totalmente el ordenamiento conduce ha consagrar un despropósito que si jurídicamente repugna a la lógica global del Estado constitucional, políticamente representa una declaración vacía, inaplicable y sin sentido, y que cualquier intento de modificación de los valores básicos que componen la fórmula política, a través del mecanismo de la reforma, implicaría no la simple sustitución de unos artículos por otros, sino la creación de un régimen político diferente y el establecimiento de un nuevo sistema constitucional. Por otra parte afirma que cuando no se admiten límites a la reforma el concepto de Constitución permite considerar como legalmente válida cualquier operación de revisión, ya que la destrucción de la Constitución material existente podrían presentarse como fenómenos deducibles del ejercicio más estricto de legalidad. (Pp 30 y 31).

21 "ARTICULO 241. A la Corte Constitucional se le confía la guarda de la integridad y supremacía de la Constitución, en los estrictos y precisos términos de este artículo. Con tal fin, cumplirá las siguientes funciones: 1. Decidir sobre las demandas de inconstitucionalidad que promuevan los ciudadanos contra los actos reformatorios de la Constitución, cualquiera que sea su origen, sólo por vicios de procedimiento en su formación (...) "ARTICULO 379. Los Actos Legislativos, la convocatoria a referendo, la consulta popular o el acto de convocación de la Asamblea Constituyente, sólo podrán ser declarados inconstitucionales cuando se violen los requisitos establecidos en este título. La acción pública contra estos actos sólo procederá dentro del año siguiente a su promulgación, con observancia de lo dispuesto en el artículo 241 numeral 2”. 
construida por la Corte, que justifica un estudio de la competencia del legislador como control formal con estudio sobre el contenido de la reforma constitucional ${ }^{22}$.

Por otra parte debe seguir el test lógico de estudio del contenido de una reforma constitucional que incluye premisas lógicas ${ }^{23}$ que aplican la teoría de los elementos esenciales de la Constitución como límites al legislativo al poder de reforma. Para el Dr. Carlos Bernal Pulido ${ }^{24}$, este punto presenta su principal desafío, ya que la formulación de dicho test enfrenta muchos problemas, incluye la definición de elemento esencial y criterios para distinguirlo de otras disposiciones, preguntas que ni en la dogmática, ni en la teoría son pacíficas. Según Bernal las hasta ahora premisas del test de sustitución componen siete $\operatorname{pasos}^{25}$ :

(i) Identificar el elemento esencial de la Constitución que puede ser remplazado;

(ii) Demostrar que este elemento esencial subyace a varias disposiciones constitucionales;

(iii) Demostrar que ese elemento es esencial;

22 La Sentencia C-551 de 2003 con Ponencia del Dr. Eduardo Montealegre Lynett, en estudio de la constitucionalidad de la Ley 796 de 2003 por medio de la cual se convocaba a un referendo y se sometía a consideración del pueblo un proyecto de Reforma Constitucional amplio el estudio de aspectos formales al estudio del contenido de la reforma que tenía relación con los siguientes temas: inhabilidades para ejercer cargos públicos, la obligación del voto nominal y públicos para los elegidos por voto popular, la prohibición de suplentes en cargos de elección popular, la obligación de audiencias públicas consultivas para la elaboración del presupuesto, la prohibición a los congresistas de participar en las funciones administrativas del Congreso, la reducción de los miembros del Senado de la República y de la Cámara de Representantes, la creación de circunscripciones especiales de paz para las elecciones públicas en representación de grupos en proceso de paz y desmovilización, la adjudicación de curules por el sistema de cifra repartidora, la ampliación de causales de pérdida de investidura de Congresistas, limitaciones de pensiones con cargo público, la supresión de contralorías, la supresión de personerías, prohibición de concesión de auxilios públicos, ampliación de la cobertura y mejoramiento de la calidad en educación, ampliación de fondos para la educación, modificación a los partidos políticos, estipulación del castigo a la producción y distribución de sustancias alucinógenas, ampliación del periodo de gobernadores y alcaldes.

23 Los intentos de la Corte Constitucional por enunciar sus criterios para estas respuestas datan desde las Sentencias C-970 de 2004 y C-971 de 2004, las cuales se resumen en la Sentencia C-141 de 2010.

24 El abogado Carlos Bernal Pulido, es considerado una autoridad en temas de derecho constitucional, no sólo por haberse graduado con tesis summa cum lade en la Universidad Externado a los 22 años por su tesis titulada La fundamentación de los principios constitucionales y su doctorado summa cum lade de la Universidad de Salamanca titulada El Principio de proporcionalidad y los derechos fundamentales bajo la dirección de José Luis Cascajo Castro, sino por sus logros en investigación en el departamento de derecho público y filosofía del derecho de la Universidad Christian - Albrecht de Kiel bajo la dirección del Prof. Dr. Robert Alexy en 2000 y su producción literaria El derecho de los derechos de 2005 y El neoconstitucionalismo a debate de 2006.

25 La Sentencia C-249 de 2012 de la Corte Constitucional, aplica un test de sustitución que declaró la inconstitucionalidad de Acto Legislativo 4 de 2011 por medio del cual se intentaba incorporar un artículo transitorio a la Constitución Política de Colombia relacionado con la homologación de las calidades de los aspirantes a ingresar y actualizar a los cargos de carrera en calidad de provisionales o en encargo. 
(iv) Probar que el contenido de tal elemento no puede ser abarcado por una sola disposición constitucional;

(v) Demostrar que catalogar el elemento sub examine como esencial no lleva consigo la petrificación de ningún elemento constitucional;

(vi) Evidenciar que el elemento esencial ha sido remplazado con otro;

(vii)Hacer patente que este nuevo elemento contradice el elemento esencial o guarda tantas diferencias con él que resulta incompatible con otros elementos esenciales de la Constitución.

Lo anterior sólo se supera si se adopta un concepto de Constitución ${ }^{26}$ ya que los elementos esenciales dependen del concepto que se tenga el cual, a su vez, requiere de una teoría constitucional. Por ejemplo, una teoría dogmática que acepta la existencia de estándares internacionales diría que una Constitución desde el artículo XVI de la Declaración de los Derechos del Hombre y del Ciudadano promulgada el 26 de Agosto de 1789 identifica como esencial primero la garantía de los derechos y segundo la determinación de la separación de los poderes, además de la consagración del principio de legalidad.

Hasta aquí si se quiere se trata de elementos para una acción con ausencia de claridad sobre los márgenes epistémicos y estructurales del juez, y de precedentes judiciales convergentes, y que enfrenta cierta desconfianza y escepticismo en quien ejerce control constitucional como guardián principal de la Constitución por lo moldeable del test de sustitución construido para casos de estudio de reformas constitucionales.

\section{Elementos frente al problema del control constitucional y convencional a las enmiendas}

"Los Derechos Humanos no nacen todos en un momento, nacen cuando pueden o deben nacer (...), ciertas garantías nacen cuando nacen ciertas necesidades (...)."

26 Loewenstein establece que existen muchos tipos de constituciones, pero que una verdadera Constitución es aquella que, además de contener normas sobre los poderes supremos y garantías esenciales, debe encarnar los más profundos valores de la democracia y la realidad del grupo de gobernados al cual se impondrá. A esto se le denomina clasificación ontológica. Así, Loewenstein considera tres tipos de Constitución: Constituciones originarias y derivadas, Constituciones ideológico-programáticas y utilitarias. En atención a la eficacia real del texto constitucional y a la forma en que es asimilado por el cuerpo social, Loewenstein distingue entre: Constitución normativa y Constitución nominal; ver también los conceptos de Carl Schimitt en Teoría de la Constitución, como un todo unitario, en sentido absoluto, como ordenación política y social, como devenir dinámico de la unidad política, en sentido relativo, en sentido positivo, como decisión, como intangible, como ideal y como pacto, entre otras. 
Al parecer el problema es principalmente axiológico según Robert Alexy ${ }^{27}$ que en este asunto destaca que es una paradoja que surge de una tensión entre dos principios constitucionales que regulan la actividad de la Corte Constitucional y la Rama Legislativa válida y legítimamente constituida en un Estado: El principio de la supremacía de la Constitución ${ }^{28}$ y el principio democrático ${ }^{29}$. El enfrentamiento surge cuando la Corte Constitucional apropiada de ser el máximo intérprete de la Constitución, define los límites constitucionales del Parlamento para reformar la Constitución $^{30}$, debate que no es nuevo ${ }^{31}$, y sigue siendo una necesidad el intento

27 Robert Alexy nació el 09 de septiembre 1945 en Oldenburg Alemania, fecha que coincide con el día nacional para Colombia de los Derechos Humanos. Filósofo del derecho y jurista de la Universidad de Georg-August-Universität Göttingen, recibió el Doctorado en derecho en 1976 con una tesis sobre Teoría de la Argumentación Jurídica dirigida por Ralf Dreir, recibió por ella el premio de la Academia de Filología Histórica de la Academia de Ciencias de Göttinga. En sus textos ha sido influenciado por Aristóteles, Immanuel Kant, Frege, Gottlob, Hans Kelsen, HLA Hart, Gustav Radbruch y Alexis Alf Ross. A raíz de la distinción de Ronald Dworkin entre reglas y principios, surge en 1986 su obra "Theorie der Grundrechte. Prinzipien seien Optimierungsgebote" con una primera edición en español traducida por Ernesto Garzón Valdés del año 1993 y una segunda traducida por el colombiano Carlos Bernal Pulido en el año 2007. Actualmente es Catedrático de Derecho Público de la Universidad Christian-Albrechts de Kiel.

28 El principio jurídico de la supremacía constitucional que se encuentra en el artículo 241 de la Constitución colombiana ha tenido una evolución jurisprudencial importante, donde la Constitución va a ser finalmente considerada fuente suprema de derecho no sólo porque es el querer y la voluntad del pueblo sino también porque ella es la norma superior del ordenamiento jurídico, donde a ella deben condicionarse todas las demás normas, pues ella es la norma que estructura el Estado y organiza la sociedad. Obsérvese especialmente la Sentencia 486 de 1993 del Magistrado Ponente Eduardo Cifuentes Muñoz y el Salvamento de voto de Carlos Gaviria Díaz.

29 Robert Alexy indica en su texto sobre la Teoría de los Derechos Fundamentales, que "Las normas de derechos fundamentales que, como las de la Ley Fundamental, vinculan al legislador, establecen lo que debe y lo que no puede decidir el legislador legitimado democráticamente", sin embargo, para esto no sólo deben considerarse las normas explícitas, sino también las normas implícitas de la Constitución.

30 En la Sentencia No. C-004 de1992 con MP Dr. Eduardo Cifuentes Muñoz puede rastrearse el inicio de una nueva era en la revisión constitucional de una reforma. A pesar de que se determinó la constitucionalidad del Decreto 333 de febrero 24 de 1992 por medio del cual se declaraba el Estado de Emergencia Social se revisó el límite de la discrecional ejecutiva, recogiendo la tesis de la necesidad de un control formal y material que sostuvo desde 1974 el magistrado Luis Sarmiento Buitrago. En la Sentencia se exponen argumentos como estos: "Carece de respetabilidad pensar que el Constituyente de Colombia, hubiera querido limitar la función de control jurisdiccional a una simple actuación notarial para lo cual no hubiera sido necesario entregar a la más alta Corporación Judicial integrada por magistrados que el propio constituyente se esforzó en revestir con la más absoluta independencia de las otras ramas del poder público. El control debe ser, en consecuencia, integral o no tiene razón de existir". La Sentencia cuenta con el Salvamento de Voto del Magistrado Ciro Angarita Barón, quien amplía los aspectos a revisar en un control material a una enmienda constitucional adoptando el test de anormalidad y de la integridad.

31 Este frente encuentra otros desarrollos como el caso Brown contra la Junta de Educación de EE.UU (1954) que prohibió la segregación de las escuelas públicas, cuya decisión se le apropia a la labor del juez Earl Warren quien desde septiembre de 1953 integraba el Tribunal Supremo de los Estados Unidos y que lideró otros fallos con el acento de activismo judicial, de donde dan cuenta también los procesos judiciales del Tribunal Constitucional de la India y el Tribunal Africano en casos del apartheid. 
judicial de fundamentar que es un control judicial y jurídico asilado de la política, en el campo de la guarda de la Constitución por los excesos y omisiones en la deliberación política.

Es muy difícil negar que es un tema de principios dentro de contexto del cambio de paradigma, así lo deja ver Aragón cuando afirma que al estar frente a una Constitución principialista, se originan unas consecuencias que han de aceptarse entre las que se cuentan el aumento del margen de discrecionalidad en la interpretación jurídica y el reforzamiento de la importancia del papel de los jueces en el Estado de derecho, que pasa ahora a ser un Estado jurisdiccional de derecho ${ }^{32}$. Del mismo modo Bernal afirma que las ideas más importantes de la teoría del Derecho contemporánea, tanto en el mundo anglosajón como en el Derecho continental, es que los ordenamientos jurídicos no están compuestos exclusivamente por reglas, es decir, por el tipo tradicional de normas jurídicas, sino también por principios ${ }^{33}$.

Al respecto Habermas al citar el Tribunal Constitucional de Alemania decía que no puede el Derecho ser igual que la totalidad de las leyes escritas, ya que frente a lo creado por el Estado puede haber a veces un plus no escrito que tiene su fuente en el orden constitucional como totalidad de sentido y que puede actuar como correctivo frente a la Ley escrita, denuncia que también sustenta Duguit en su crítica a Kelsen. Encontrar ese plus según Habermas, es función de la jurisprudencia constitucional, de la 'argumentación racional', en fase de control difuso o abstracto de constitucionalidad, incorporar nuevos elementos axiológicos, lo cual no puede significar la impureza del Derecho sino el reconocimiento de lo que es el Derecho.

En Dworkin también puede rastrearse una defensa por observar los principios constitucionales, lo cual incluye al poder judicial como un "foro de principios" que encaja dentro de la defensa de lo justo sin salirse del ordenamiento jurídico prestablecido con un concepto legalista de justicia. Paolo Comanducci ${ }^{34}$ frente a este tema, afirma que el principio democrático no existe sin Constitución y que la Constitución depende de la democracia, y que así mismo la democracia y la Constitución se ponen límites, siendo la Constitución una norma a ser interpretada por su máximo guardián y la democracia ejercida por la rama legislativa, estos dos principios son necesarios y suficientes, y frente a esta realidad son guía para dirimir los diferentes problemas jurídicos relacionados con la competencia de la Corte y

32 ARAGÓN, Manuel, El juez ordinario entre legalidad y constitucionalidad", Instituto de Estudios Constitucionales Carlos Restrepo Piedrahíta, p. 23.

33 BERNAL, Carlos, El Derecho de los Derechos. Escritos sobre la aplicación de los derechos fundamentales, Universidad Externado.

34 El italiano Paolo Comanducci, Decano y Profesor de Filosofía del Derecho en la Universidad de Génova, y Doctor Honoris causa de la Universidad de Córdoba Argentina, actualmente junto con Riccardo Guastini, edita desde 1990 el Anuario de Estudios Teóricos "Analisi e diritto. Ricerche di giurisprudenza analítica", y coordina una colección de ensayos con el mismo título, también es codirector de la revista "Ragion practica" y "Materiali per una storia della cultura giuridica". 
la competencia del Legislador, dentro una época ${ }^{35}$ del constitucionalismo $^{36}$ en transformación.

Esta fundamentación por lo axiológico, desemboca evidentemente en problemas de interpretación ${ }^{37}$ constitucional que, a su vez, enfrenta mostrar preferencia por ciertos cánones constitucionales ${ }^{38}$, la escogencia de una de ellas evidencia en parte el tipo de construcción escogido ${ }^{39}$. Por ejemplo, una teoría positivista conservadora del statu quo preferiría un estricto control formal constitucional derivada de una interpretación explícita de la Constitución Colombiana por parte de la Corte, una teoría pragmática llevaría a depender del contexto o del caso concreto evidenciando amplio margen discrecional y relevancia en la interpretación, y para algunos será de preferencia los nuevos cambios de tesis orientados a los estándares internacionales,

35 En relación al uso de la palabra época, surgen distintos fines que incluso comportan varios sinónimos como era o tiempo como el caso de Norberto Bobbio. Rapto este título en este caso especialmente del texto de 1998 de SABATER, José “La Época del Constitucionalismo" que de manera arraigada intenta usar la palabra para plantear entre otros fundamentos la necesidad de un constitucionalismo para la comunidad, y que sirve de ejemplo para argumentar que existen distintas formas de abordar una época, una era o el tiempo del constitucionalismo contemporáneo, que dependen del enfoque, de la ciencia y de la teoría aplicada.

36 El constitucionalismo además de enfrentar etapas en su proceso de omnipresencia en un ordenamiento jurídico, también enfrenta distintas "olas" que dependen del tono de su intento de inclusión social. Para CARBONELL, Miguel, en su ponencia "Contexto, Retos y Agenda del Derecho Constitucional” expuesta en la Universidad Santo Tomás (B/manga-Col) en mayo de 2010, es claro que además de los elementos mínimos para una constitucionalización y de la construcción de una "buena" teoría de la argumentación, existe una agenda progresista del derecho constitucional que incluye la omnipresencia de la Constitución en el ordenamiento jurídico y en la actividad judicial, la cual para este caso concreto, espera un papel activo y una evaluación de las normas por parte de la Corte Constitucional, por ser el "Guardián de valores encargados de defenderlo de los caprichos del legislador".

37 BOBBIO, Norberto, al referirse a la interpretación del derecho en su texto El problema del positivismo jurídico, proyecta la interpretación de las leyes como un cuarto significado de una teoría formalista, en ella señala que el método adoptado junto con la función atribuida al intérprete, son caracteres que identifican una posición conservadora o progresista dada a la interpretación. Al ubicar a un juez como progresista se adopta este tipo de distinción, peor más aún cuando se dirige respecto a la función, la cual identifica a un juez meramente declarativo de las leyes vigentes, o a un juez con la función incluso de crear un nuevo derecho.

38 CARBONELL, M.; GARCÍA, L. (2010). El Canon Neoconstitucional. Con foto como portada de la Escultura de "Cronos” Dios del Tiempo Humano. Universidad Externado. Bogotá.

39 Hasta aquí podría decirse que se explica las principales condiciones de constitucionalización, las cuales de manera casi que taxativa describe Paolo Comanducci en Constitucionalización y neoconstitucionalismo siguiendo a Guastini, así: 1. La existencia de una constitución rígida que incorpore los derechos fundamentales. 2. La garantía de la Constitución. 3. La fuerza vinculante de la Constitución (que no es un conjunto de normas programáticas sino preceptivas). 4. La sobreinterpretación de la Constitución (se le interpreta extensivamente y de ella se deducen principios implícitos). 5. La aplicación directa de las normas constitucionales, también en las relaciones entre particulares. 6. La interpretación adecuada de las leyes. 7. La influencia de la Constitución sobre el debate político. 
que pueden ir hasta el extremo de sustentar el control convencional al control constitucional o la supremacía de la Convención Interamericana a la supremacía de la Constitución Política ${ }^{40}$. La elección pasa por teorías exegéticas o dogmáticas, por reflexiones sobre el derecho válido o los fines sociales del derecho, por preservar los conceptos formales o la ampliación del sistema de normas ${ }^{41}$.

Así las cosas, surge una innegable necesidad de fundamentar las razones y el alcance de la interpretación escogida, preferiblemente con criterios de distinción ${ }^{42}$ dentro de una teoría de la argumentación. Paolo Comanducci aceptada la naturaleza dual de las normas constitucionales, identifica la interpretación constitucional desde varias formas ${ }^{43}$, y considera que una sobre-interpretación de la Constitución por parte del máximo juez constitucional se puede justificar, si se interpreta extensivamente sus disposiciones ${ }^{44}$ a través de una plataforma argumentativa que sustente una interpretación valorativa ético-material que acepta un concepto moral de la Constitución.

Dicha argumentación parte de un concepto sobre la naturaleza de la Constitución, la cual es múltiple. Comanducci distingue cuatro posibles respuestas desde los teóricos. La primera como cognitiva del modelo descriptivo de la Constitución, la segunda decisional del modelo descriptivo , la tercera como cognitiva del modelo axiológico , y por último la decisional del modelo axiológico. Respecto a la especificidad de la Constitución distingue dos métodos, un enfoque empírico y un enfoque normativo. Los enfoques empíricos serían aplicadores de la teoría de la interpretación decisional y la interpretación cognitiva descriptiva, y los enfoques normativos aplicarían la interpretación descriptiva o la interpretación cognitiva axiológica, sin ser los únicos.

Según se adopte una u otra tesis, se prefiere una Constitución conceptualmente independiente de la interpretación de los Tribunales Constitucionales, o el determinar que la Constitución es lo que interpreten los Tribunales Constitucionales, o una tarea

40 REY, Ernesto, Control de convencionalidad de las leyes y derechos humanos, Homenaje a Héctor Fix-Zamudio, Biblioteca Porrúa de Derecho Procesal Constitucional No. 26, Instituto Mexicano de Derecho Procesal Constitucional, Editorial Porrúa, México, p. 46.

41 Es así como Rudolf von Ihering impulsa la jurisprudencia de intereses, cuyo leimotiv es que el fin es el creador del derecho y que no existe ninguna norma jurídica que no deba su origen a algún fin. Esta orientación fue desarrollada, ya en el siglo XX por el movimiento del derecho libre, propugnador de la libertad del jurista, en especial la del juez, para integrarla, e incluso corregir, el derecho positivo a partir de los valores y principios morales y políticos vigentes en una sociedad.

42 Riccardo Guastini publica su texto Distinguiendo. Estudios de teoría y metateoría del derecho, influenciado en parte por la fórmula expuesta por Norberto Bobbio en El problema del positivismo Jurídico de distinguir las formas en las que se presentan las teorías del derecho, y teniendo como referencia las concepciones de Tarello sobre la meta-jurisprudencia y la filosofía analítica del derecho.

43 COMANDUCCI, Paolo, Formas de (neo)constitucionalismo: un análisis metateórico. Revista Isonomía No.16 año 2000 pp 89-112 traducción de Miguel Carbonell, México.

44 GUASTINI, Ricardo, Estudios de teoría constitucional, año 200, UNAM Fontamara, México. 
interpretativa de la Constitución llevada discrecionalmente por múltiples sujetos en cooperación, negociación e interpretación, pero también en competencia entre sí para afirmar un sentido de Constitución.

Para el caso sobre la interpretación extensiva al artículo 241 de la Constitución, una perspectiva interpretativa diría que la preferencia por una interpretación literal frente a la histórica y la teleológica de este artículo, comporta una defensa de lo indefendible, sobre todo, cuando se parte de ejemplos como los antes descritos. Una tesis al respecto que identifique esta tensión y describa uno de los bandos como preferente de una función formalista de la Corte que tenga al juez con poder meramente de revisión formal de las enmiendas aplicando el método tradicional y desestimando la jurisprudencia realista ${ }^{45}$, lo encontramos en Bobbio. El jurista italiano sobre este problema interpretativo después de identificar los bandos concluye, que en verdad, ya nadie cree que las operaciones realizadas por el juez para interpretar el derecho sean exclusivamente operaciones lógicas en el sentido estricto de la palabra, es decir, operaciones de deducción de ciertas conclusiones a partir de determinadas premisas ${ }^{46}$, con otras palabras, que la actividad del juez no puede ser estrictamente mecánica o automática, el mismo Kelsen concibe la interpretación como un proceso espiritual $^{47}$.

Hasta aquí podría concluirse que desde la teoría hay una aceptación general de un control constitucional extensivo por parte de la Corte, lo problemático es el tipo de argumentación que se prefiera para auscultar cuestiones lógico-lingüísticas, sin embargo, no se acepta el radicalismo de una simple verificación de las votaciones, los términos y el quórum, en un proceso de reforma, una especie de ubi non est iustitia, ibi non potest esse jus, que afianza la necesidad de escoger una tesis para construir y revisar las subreglas para la revisión de los actos de reforma constitucional, o que coteje si las creadas por la dogmática jurisprudencial son las adecuadas. El profesor García de Enterría, concluye muy fino esta parte, cuando dice que es de la Ley humana que no existan panaceas, pero que la jurisdicción constitucional hoy es el más eficaz de los instrumentos de integración política y social que las sociedades avanzadas conocen ${ }^{48}$, para lo cual los tribunales constitucionales deben aprender a trabajar con principios y conceptos constitucionales indeterminados y a veces con principios y conceptos no explícitos, o que son extraídos de otros que sí lo son, trabajo que ahora se traslada para los actores de acciones.

45 Ejemplos de este tipo de Sentencias es el Caso William Marbury vs. James Madison de 1804 del juez constitucional estadounidense John Marshall. Esta Sentencia describe al Estado como un gobierno limitado por mandato de la Constitución, que impone límites a la actuación de los poderes públicos, que lleva a la conclusión que la Constitución controla cualquier acto legislativo que le sea "repugnante", razonamientos que no han sido ausentes de crítica pero que evidencian para la época un avance más que un retroceso en la teoría constitucional. Al respecto ver CARBONELL, Miguel, en ¿El Tercero Ausente? Ensayos sobre el Poder Judicial, México, Porrúa, UNAM, 2008.

46 BOBBIO, Norberto, Interpretación Formal del Derecho en El problema del positivismo jurídico, Editorial Fontamara, traducido por Ernesto Garzón Valdez. 


\title{
5. Reflexiones finales: hacia una metafísica del control constitucional
}

\author{
"No seguirás a la mayoría para hacer el mal"
}

Éxodo, $23: 2$

Frente a los riesgos de un desborde de los límites del poder de reforma derivado, se identificó como su némesis la sustitución constitucional, lo cual terminó en la construcción de un concepto de sustitución y en una indagación sobre las propiedades esenciales de una Constitución, por otra parte, esto repercutió en el concepto de Constitución, en el concepto de derecho que recae históricamente en el problema acerca de si el derecho debe contener elementos morales.

El problema puede así clasificarse como conceptual y metodológico, los dos inclinados a imponer obligaciones en la Corte Constitucional como contrapeso al problema de discrecionalidad judicial de estudio material de reformas, o incluso al problema de valoraciones políticas, ideológicas o contextuales ${ }^{49}$. Lo conceptual debe resolver una noción de Constitución ${ }^{50}$ y de elementos esenciales de la misma, para dar paso a definir el método que identifica los elementos esenciales en riesgo, que se caracterizan como vitales desde lo acordado por la Asamblea Nacional Constituyente como resultado de la deliberación ${ }^{51}$, o que han podido ser introducidos posteriormente y que adquieren el carácter de esencial (como nuevos derechos fundamentales o producto de tratados internacionales suscritos), como los que se entienden prexistentes al mismo pacto (ejemplo la dogmática internacional en derechos humanos y democracia). Esto al parecer identifica una triple dimensión conceptual y metodológica, en relación con un concepto y un método de control

49 Miguel Carbonell en la Revista Estudios Constitucionales Año 6 No.2 2008, de la Universidad de Talca Chile, en la página 565 de Gustavo Zagrebelsky, juez constitucional cierra su escrito recordando que los jueces constitucionales no deben estar atados a lo que les dicte la opinión pública, y que según Zagrebelsky desde su experiencia como juez, muchas veces se toman decisiones impopulares, por tanto, los jueces no deben dejarse influenciar bajo ningún tipo de presión, y cita a Zagrebelsky "Si cedieran a la tentación de recurrir al consenso popular, no sólo traicionarían completamente su función sino que se dejarían seducir por cantos de sirena que los conducirían al desastre"

50 Luigi Ferrajoli propone en Principia Iuris el concepto de Constitución Democrática derivada de una teoría de la democracia desde el aparato conceptual de la teoría axiomatizada del derecho, el sistema de los límites, vínculos, controles y separaciones impuesto a los distintos tipos de poderes del paradigma constitucional, que vincula un modelo normativo formal y sustancial de democracia articulado en un modelo cuatridimensional correspondientes a otras tantas clases de derechos constitucionalmente establecidos.

51 La Corte Constitucional en la Sentencia C-141 de 2010 cuando con base en las intervenciones ciudadanas entra a desarrollar el alcance de la expresión "solo por vicios del procedimiento en su formación" contenida en el artículo 241.2 de la Constitución y la competencia de la Corte Constitucional para examinar los vicios de competencia de la ley convocatoria a un referendo constitucional, afirmó que ni la existencia de una Asamblea Constituyente hace desaparecer del todo los límites de reforma, pues aunque ya no provendrían de lo dispuesto en la Constitución sustituida, tendrían su origen en las normas imperativas de derecho internacional y también en los convenios internacionales de derechos humanos. 
sobre lo acordado, otra sobre lo creado, y otra sobre lo que se entiende prexistente al mismo pacto social.

La concepción de Reinach ${ }^{52}$ es muy útil aquí ya que dice que, a pesar de que según la historia, el derecho es cambiante, existen unos elementos que no mutan y que son esenciales en el derecho, esta reflexión puede suponer el ingreso de la teoría de las disposiciones naturales, esenciales y accidentales dentro del acuerdo de habla, y que el problema conceptual no es de las cláusulas naturales o de las accidentales, sino de las normas fundamentales. Los derechos fundamentales pueden ser esenciales y naturales, son esenciales cuando ya han sido concretados taxativamente o desde una dogmática, y es aquí donde adoptan el criterio de insustituibles como, por ejemplo, la prohibición de la pena de muerte como derecho fundamental prestacional en sentido amplio adscrito al derecho de defensa a la vida.

Por otra parte respecto a la forma de gobierno ${ }^{53}$ pactada como valor histórico ${ }^{54}$ y cultura $1^{55}$ que dan identidad y un espíritu a la norma de normas ${ }^{56}$, podría decirse también que tiene dos dimensiones, una natural y otra esencial. Cuando se habla sobre aspectos y criterios universales de la democracia se está aceptando sólo estándares globales, lo cual supone imperativos a los Estados Constitucionales, que coexistirían con pactos democráticos domésticos con igual dimensión de importancia, que al ser locales comportan en la Constitución la naturaleza de disposiciones esenciales que no pueden ser sustituidas, algo así como reglas de juego democráticas concretas que albergan protección a su vez de otros principios como, por ejemplo, el principio de frenos y contrapesos.

52 REINACH, Adolf, Los fundamentos "a priori" del Derecho Civil, colección filosofía, derecho y sociedad, editorial comares.

53 Aristóteles en el Libro VI de La Política analiza diferentes formas de gobierno, incluida la democracia, en relación con el análisis de lo que puede entenderse como 'libertad política'

54 En el libro El Federalista se justificó la rigidez de la reforma constitucional de la Constitución estadounidense desde el espíritu de los Padres Fundadores inspirado en un concepto de Constitución Anglosajón que se adhiere a la existencia de un derecho superior más allá de las leyes existentes o escritas, un Derecho consuetudinario que hace parte de la historia cultural y política, en este caso, del Estado de Inglaterra, un "Derecho más alto" porque no se puede tocar, un Derecho de valores y de principios supra-legales que integran el patrimonio cultural de un pueblo; sobre las formas de gobierno ver La Política de Aristóteles

55 Para Peter Haberle en su texto El Estado constitucional una Constitución está compuesta por elementos ideales y reales, entre ellos resalta la dignidad humana pero, dentro del contexto que para su realización depende de la cultura de un pueblo y de los derechos universales de la humanidad, por tanto, la dignidad depende de los acontecimientos "vividos desde la individualidad de ese pueblo, que encuentra su identidad en tradiciones y experiencias históricas" ( p. 1).

56 Mauricio García Villegas, desde la teoría crítica, cuestiona en Las normas de papel (2011) la cultura del incumplimiento de las reglas en América Latina, desde un enfoque histórico y sociológico demuestra cómo desde los tiempos de la colonia escritores, pensadores y gobernantes se han referido a la inobservancia de reglas. Según el autor una remembranza en el espíritu de la ley lleva a un estado de legitimidad del poder, una aceptación en la imposición de sanciones y un establecimiento de una cultura de cumplimiento de las normas. 
Todo al parecer está por construir y hay un camino, sin embargo, preguntas como si ¿Es cláusula esencial de la Constitución su preámbulo? o si ¿La separación de poderes en abstracto ya no fue remplazada?, originan cierta desconfianza en el remedio metodológico hasta ahora examinado y aplicado por la Corte para identificar una sustitución de un elemento esencial, incluso se cuestiona si el examen lógico axiológico y los criterios de racionalidad escogidos para la toma de decisiones jurídicas se encuentran afectados, y si los criterios de racionalidad son a vivas luces premisas que exigen hiperracionalismo y que presuponen cognitivismos metafísicos ${ }^{57}$.

Del mismo modo se debe examinar si las propuestas metodológicas de los teóricos como Robert Alexy proponen métodos aplicables para casos que aborden colisión de principios constitucionales, si el aceptar la concepción de una Constitución compuesta por reglas y principios distingue las posiciones jurídicas constitucionales definitivas, si las disposiciones constitucionales como mandatos de optimización dentro de la mayor medida posible dependiendo para su realización de las condiciones fácticas y jurídicas disponibles son esenciales al pacto, todo para explicar los criterios lógicos, razonables y objetivos adoptados.

Finalmente, el reflexionar sobre el costo por llegar a la garantía de los derechos fundamentales y el camino para llegar a la consolidación de la democracia, es un valor axiológico constitucional, que si bien es cierto sigue en construcción, se entiende como una carta de triunfo dentro del desarrollo histórico pasado y vigente, por tanto, retroceder en los avances implicaría sustituir el pacto y justificaría un foro de principios para proteger lo que está o, si se quiere también, para razonar sobre introducciones nuevas (Ejem: anteponer la dignidad colectiva sobre la dignidad individual, o deliberación racional sobre la democracia procedimental).

\section{REFERENCIAS}

Alexy, R. (2008). El Concepto y la Naturaleza del Derecho, Marial Pons Ediciones Jurídicas y Sociales, traducción y estudio introductorio de Carlos Bernal Pulido, Madrid/Barcelona/Buenos Aires.

Alexy, R. (2007). Teoría de los Derechos Fundamentales, Centro de Estudios Constitucionales, segunda edición en castellano, traducida por Carlos Bernal Pulido, Madrid.

Alexy, R. (2003). Tres Escritos sobre los Derechos Fundamentales y la Teoría de los Principios, Universidad Externado de Colombia, presentación y traducción de

57 BERNAL, Carlos, El neoconstitucionalismo y la normatividad del derecho, Universidad Externado, 2009, Bogotá, p. 24. 
Carlos Bernal Pulido, Bogotá.

Alexy, R. (1994). El Concepto y la Validez del Derecho, traducción de Jorge M. Seña, Editorial Gedisa, Barcelona.

Alexy, R. (1989). Teoría de la Argumentación Jurídica. La Teoría del Discurso Racional como Teoría de la Fundamentación Jurídica, traducido por Manuel Atienza e Isabel Espejo, Centro de Estudios Constitucionales, Madrid.

Atienza, M. (2006). El Derecho como Argumentación, Editorial A r i e 1 , colección derecho.

Aristóteles (1831-186). La Política, dentro del Corpus Aristotélico editado según la edición prusiana de Immanuel Bekker, 1252a.

Aragón, M. (1997). El Juez Ordinario entre Legalidad y Constitucionalidad, Instituto de Estudios Constitucionales Carlos Restrepo Piedrahíta, Bogotá.

Bernal, C. (2007). El Principio de Proporcionalidad y los Derechos Fundamentales. El Principio de Proporcionalidad como Criterio para Determinar el Contenido de los Derechos Fundamentales Vinculante para el Legislador, Centro de Estudios Políticos y Constitucionales, Tercera Edición, Madrid.

Bernal, C. (2005). El Derecho de los Derechos. Escritos sobre la Aplicación de los Derechos Fundamentales, Universidad Externado, Bogotá.

Bernal, C. (2009). El Neoconstitucionalismo y la Normatividad del Derecho. Escritos de Derecho Constitucional y Filosofía del Derecho, Universidad Externado, Serie intermedia de teoría jurídica y filosofía del derecho No.7, Bogotá.

Bobbio, N. (2004). El Problema del Positivismo Jurídico, Editorial Fontamara, traducción de la primera edición de 1965 por Ernesto Garzón Valdez, México.

Bobbio, N. (1999). Liberalismo y Democracia, Breviarios del Fondo de Cultura Económica, traducción de José F. Fernández Santillán de la primera edición en italiano de 1985.

Bobbio, N. (1991). El Tiempo de los Derechos, Traducción de Rafael de Asís Roig, Editorial Sistema, Madrid.

Bobbio, N. (1985). El Futuro de la Democracia, Política y Derecho, Barcelona

Cajas, M. (2008). El Control Judicial a la Reforma Constitucional. Colombia, 19102007.

Universidad ICESI, Calí.

Carbonell, M.; García, L. (2010). El Canon Neoconstitucional, Poder Judicial y Neoconstitucionalismo, Universidad Externado de Colombia, Serie intermedia de teoría jurídica y filosofía del derecho No.8, Bogotá.

Carbonell, M. (2001). Constitución, Reforma Constitucional y Fuentes del Derecho en México, Editorial Porrúa, México.

Comanducci, P. (2009). Razonamiento Jurídico: Elementos para un modelo, Editorial Fontamara, No. 68, México.

Correa, J. (2011). Inaplicabilidad por Inconstitucionalidad en la Jurisprudencia del 
Tribunal Constitucional, Editorial Legal Publishing, Santiago.

Cuadernos de Derecho Público No. 4 (2011). Universidad Sergio Arboleda, edición julio-diciembre; Rojas, H., Reflexiones sobre los límites implícitos en la reforma de la constitución pp. 15-24; Motta, A., La estabilidad de la Constitución para la vigencia de los derechos pp. 25-33; Téllez, L., Orígenes de la teoría de la sustitución de la constitución pp. 51-65; Zambrano, D., Una mirada jurisprudencial y conceptual a la sustitución de constitución: Demanda de inconstitucionalidad contra el art. 1 (parcial del acto legislativo 2 de 2009 por el cual se reforma el art. 49 de la Constitución Política pp. 67-76; Loaiza, J., El juicio de sustitución, creación de principios constitucionales inmodificables pp. 77-83.

De Vega García, P. (1985). La Reforma Constitucional y la Problemática del Poder Constituyente. Madrid.

Duguit, L. (2005). Manual de Derecho Constitucional, Colección Crítica del Derecho, primera edición.

Dworkin, R. (2012). Una Cuestión de Principios. Editorial Siglo XXI, primera traducción al castellano.

Elster, J. (1991). Juicios Salomónicos: Las Limitaciones de la Racionalidad como Principio de Decisión, traducción de Carlos Gardini, Editorial Gedisa, Colección racionalismo, razón, psicología social, Barcelona.

García de Enterría, E. (2006). La Constitución como Norma y el Tribunal Constitucional, Editorial Thomson, cuarta edición.

Guerrero, F. (2010). Responsabilidad del Estado Colombiano en el Marco del Derecho Fundamental al Territorio Ancestral y su Acceso a la Justicia Interamericana, Revista Iustitia No. 8, pp, 425-451, Universidad Santo Tomás, Bucaramanga.

Guastini, R. (2001). Estudios de Teoría Constitucional, Editorial Fontamara, Colección Doctrina Jurídica Contemporánea, México.

Ferrajoli, L. (2001). Derecho y Razón. Teoría del Garantismo Penal, Editorial Trotta, Colección Estructuras y Procesos, Serie Derecho, Madrid

Ferrajoli, L. (2011). Principia Iuris. Teoría del derecho y de la democracia. Tomo II. Editorial Gius. Laterza \& Figli SpA, Traducción a castellano del original de 2007 por Perfecto Andrés Ibáñez, Juan Carlos Bayón, Marina Gascón, Luis Prieto Sanchís y Alfonso Ruiz Miguel. Madrid.

Habermas, J. (1998). Facticidad y Validez. Editorial Trotta, traducción de Manuel Jiménez Redondo, Madrid.

Hart, J. (2001). Democracia y Desconfianza: Una Teoría del Control Constitucional, Siglo del Hombre Editores. Universidad de los Andes, Bogotá.

Hernández, J. (2011). Argumentación Jurídica, Oxford University Press, Segunda Reimpresión, México.

Hernández, J.; Castañeda D. (2009). Curso de Filosofía del Derecho, Oxford University Press, México. 
Kelsen, H. (2008). La garantía jurisdiccional de la Constitución (la justicia constitucional), en Revista Iberoamericana de Derecho Procesal Constitucional No. 10, julio-diciembre, pp. 3-46, traducción de Rolando Tamayo y Salmoran, revisada por Domingo García Belaun, de la traducción hecha al francés por Charles Eisenmann en Revue du Droit Public et de la Science Politique, Paris, avril-mai-juin 1928, tomo 45, pp. 197-257, de la conferencia presentada originalmente en Viena los días 23 y 24 de abril de 1928.

Kelsen, H. (1993). Teoría Pura del Derecho, traducción del original por Roberto J. Vernengo, séptima edición, Editorial Porrúa S.A., México

Kelsen, H. (1977). Esencia y Valor de la Democracia, traducción al castellano del original de 1929, Barcelona

Kelsen, H. (1958). Teoría General del Derecho y del Estado, traducción del original de 1945 por García Máynez, UNAM, México.

Mill, J. (2001). Consideraciones sobre el Gobierno Representativo, Alianza Editorial, Madrid.

Ordoñez, A. (2007). El Nuevo Derecho, el Nuevo Orden Mundial y la Revolución Cultural, Editorial Doctrina y Ley, Bogotá.

Quinche, M. (2012). Derecho Constitucional Colombiano. De la Carta de 1991 y sus Reformas, Temis, quinta edición, Bogotá.

Rey, E. (2008). Control de Convencionalidad de las Leyes y Derechos Humanos, Homenaje a Héctor Fix-Zamudio, Biblioteca Porrúa de Derecho Procesal Constitucional No. 26, Instituto Mexicano de Derecho Procesal Constitucional, Editorial Porrúa, México.

Rodríguez, J. (2002). Formalismo Ético y Constitucionalismo, Editorial Tirant lo Blanch, primera edición.

Schimitt, C. (1982). Teoría de la Constitución, Traducción al español por Ayala F. del texto original de 1928, Madrid.

Vigo, R. (2004). Injusticia Extrema no es Derecho (De Radbruch a Alexy), Editorial La Ley, primera edición.

Waldron, J. (2005). Derecho y Desacuerdos, Oxford University Press, traducción de José Luis Martí y Águeda Quiroga.

Whittington, K. (2001). Interpretación Constitucional: El Significado Textual, la Intención Original, y Revisión Judicial, University Press of Kansas.

Zagrebelsky, G. (2008). Principios y Votos. El Tribunal Constitucional y la Política, traducido al castellano por Manuel Martínez Neira, Editorial Trotta, Madrid.

Acto Legislativo No. 01 de 2012. Por medio del cual se establecen instrumentos jurídicos de justicia transicional en el marco del artículo 22 de la Constitución Política y se dictan otras disposiciones.

Acto Legislativo No. 05 de 2011. Por el cual se constituye el sistema general de regalías, se modifican los artículos 360 y 361 de la Constitución Política y se 
dictan otras disposiciones sobre el régimen de regalías y compensaciones.

Acto Legislativo 03 de 2011. Por el cual se establece el principio de la sostenibilidad fiscal.

Carta de la Organización de los Estados Americanos, suscrita en Bogotá en 1948 y reformada por el Protocolo de Buenos Aires en 1967, por el Protocolo de Cartagena de Indias en 1985, por el Protocolo de Washington en 1992, y por el Protocolo de Managua en 1993.

Carta Democrática Interamericana, del 11 de septiembre de 2001, dentro del vigésimo octavo período extraordinario de sesiones.

Corte Constitucional; Auto No. 062 de 2000 sobre la nulidad de la Sentencia C-642 del 31 de mayo de 2000, proferida por la Sala Plena de la Corporación.

. Auto No. 050 de 2000 sobre estudio de nulidad de la Sentencia T-157 del 22 de febrero de 2000.

Auto $\mathrm{N}^{\circ} 156$ de 2008 que declara falta de competencia para emitir un nuevo pronunciamiento sobre el Acto Legislativo 02 de 2004 en relación con el numeral $8^{\circ}$ de la parte resolutiva de la Sentencia de la Corte Suprema de Justicia, Sala de Casación Penal, fechada el 26 de junio de 2008

Auto $\mathrm{N}^{\mathrm{o}} 155$ de 2008 que rechaza recurso extraordinario de revisión contra la Sentencia C-1040 de 2005, por existencia de vicios de procedimiento en la adopción del Acto Legislativo 02 del 2004 que aprobó la relección.

. Auto 137 de 2006 que niega la nulidad de la Sentencia C-1040 de 2005 que declaró exequible el Acto No. 02 de 2004 que aprobó la relección.

Comunicado No. 9, Febrero 26 de 2010, en relación con el expediente CRF-003 Sentencia C-141 de 2010 con Magistrado Ponente Humberto Antonio Sierra Porto, por medio de la cual se decide sobre la constitucionalidad de la Ley 1354 de 2009 convocatoria a un referendo.

. Sala Segunda de Revisión, Sentencia C-141 de 2010, Magistrado Ponente Humberto Sierra Porto, de revisión de constitucionalidad de la Ley 1354 de 2009 que intentaba convocar a un referendo constitucional y someter a consideración del pueblo un proyecto de reforma constitucional.

. Sala Plena, Sentencia C-1040 de 2005, Magistrado Ponente Rodrigo Escobar Gil, aquí la Corte analiza las Sentencias C-551 de 2003, C-970 y C-971 de 2004

Sentencia C-816 de 2004, Magistrados Ponentes: Dr. Jaime Córdoba Triviño y Dr. Rodrigo Uprimny Yepes, que resuelve demanda de inconstitucionalidad contra el Acto Legislativo No. 02 de 2003 "por medio del cual se modifican los artículos 15, 24, 28 y 250 de la Constitución Política de Colombia para enfrentar el terrorismo". . Sentencia C-668 de 2004, Magistrado Ponente Alfredo Beltrán Sierra. . Sala Segunda de Revisión, Sentencia C-551 de 2003. .; Salvamento de voto del Magistrado Jaime Araújo Rentería al Auto 156 
de 2008, en relación con el mandato de de la Sentencia de la Corte Suprema de Justicia No.173 del 26 de junio del 2008.

. Salvamento de voto del Magistrado Jaime Araújo Rentería al Auto 155 de 2008, que rechazó de plano recurso extraordinario de revisión presentado contra la Sentencia C-1040 del 19 de octubre de 2005. . Salvamento de Voto del Magistrado (e) Rodrigo Uprimny Yepes a la Sentencia C-688 de 2004.

Corte Suprema de Justicia; Sala Plena, Sentencia No. 173 de 2008, que profiere sentencia anticipada dentro del proceso adelantado contra Yidis Medina Padilla por aceptación de cargos por el delito de cohecho propio.

- Sentencia No. 138 de 1990 de revisión Constitucional del Decreto Legislativo No. 1926 de 1990, por la cual se regula la convocatoria a una Asamblea Constitucional, Magistrados Ponentes: Hernando Gómez Otálora, Fabio Morón Díaz.

Constitución Política de Colombia de 1991.

Decreto 1351 de 2012. Por medio del cual se convoca al Congreso de la República a Sesiones Extraordinarias para revisión de objeciones presenciales al proyecto de Acto Legislativo No. 7 de 2011.

2067 de 1991. Por el cual se dicta el régimen procedimental de los juicios y actuaciones que deban surtirse ante la Corte Constitucional.

1926 de 1990. Por el cual se regula la convocatoria a una Asamblea Constitucional.

Ley 5 de 1992. Capítulo VII Del Proceso Legislativo Constituyente.

Presidencia de la República. Objeciones Presidenciales al Proyecto de Acto Legislativo № 07 de 2011 Senado-143 de 2011 Cámara, acumulado a los proyectos 09/11, 11/11, 12/11 y 13/11 Senado "por medio del cual se reforman artículos de la Constitución Política con relación a la Administración de Justicia y se dictan otras disposiciones". 